\title{
METHANOLACINIA GEN. NOV., INCORPORATING METHANOMICROBIUM PAYNTERI AS METHANOLACINIA PAYNTERI COMB. NOV.
}

\author{
GERHARD ZELLNER, ${ }^{1}$ PAUL MESSNER, ${ }^{2}$ HELMUT KNEIFEL, ${ }^{3}$ \\ BRIAN J. TINDALL,${ }^{4}$ JOSEF WINTER,${ }^{*, 1}$ AND ERKO STACKEBRANDT ${ }^{5}$ \\ ${ }^{1}$ Institut für Mikrobiologie, Universität Regensburg, Universitätsstr. \\ 31, D-8400 Regensburg, FRG \\ ${ }^{2}$ Zentrum für Ultrastrukturforschung, Universität für Bodenkultur, Gregor-Mendel-Str. \\ 33, A-1180 Vienna, Austria \\ ${ }^{3}$ KFA Jülich, Institut für Biotechnologie 3, Postfach 1913, D-5170 Jülich, FRG \\ ${ }^{4}$ DSM-Deutsche Sammlung von Mikroorganismen und Zellkulturen GmbH, \\ Mascheroder Weg 1b, D-3300 Braunschweig, FRG \\ ${ }^{5}$ Institut für Allgemeine Mikrobiologie, Biologiezentrum, Universität Kiel, \\ Olshausenstr. 40-60, D-2300 Kiel, FRG
}

(Received March 29, 1989)

On the basis of an extended investigation of morphological, biochemical and physiological properties and its phylogenetic affiliation it is proposed to place Methanomicrobium paynteri (Rivard et al. 1983, 24), validly published in 1984 (Rivard et al. 1984, 25) within a new genus, Methanolacinia gen. nov. as Methanolacinia paynteri comb. nov.

Its cell envelope consists of a cytoplasmic membrane and a hexagonally arranged S-layer with a lattice constant of the geometrical subunits of $15.3 \mathrm{~nm}$, while the periodic structures on the cell envelope of Methanomicrobium mobile were not characterized. The S-layer contains a glycoprotein subunit with an apparent molecular weight of 155,000. The polyamine pattern of Methanolacinia paynteri is comparable to that of Methanogenium species but differs significantly from that of Methanomicrobium mobile. Comparative lipid analyses of Methanomicrobium mobile, Methanogenium cariaci, Methanospirillum hungatei and Methanolacinia paynteri reveal marked differences. Furthermore, Methanolacinia paynteri grows not only on $\mathrm{H}_{2} / \mathrm{CO}_{2}$ as reported, but also on 2-propanol $/ \mathrm{CO}_{2}$, 2-butanol $/ \mathrm{CO}_{2}$ and cyclopentanol $/ \mathrm{CO}_{2}$.

Together with the low $S_{\mathrm{AB}}$-value of 0.51 , which Methanolacinia paynteri shares with Methanomicrobium mobile, these features corroborate the proposed reclassification.

\footnotetext{
* Address reprint requests to: Dr. Josef Winter, Institut für Mikrobiologie, Universität Regensburg, Universitätsstr. 31, D-8400 Regensburg, FRG.
} 
Methanomicrobium paynteri, a mesophilic, non-motile, pleomorphic methanogen, isolated from a marine sediment, was allocated to the genus Methanomicrobium on the basis of morphological criteria and a weak reaction with antiMethanomicrobium mobile S-probe $(24,25)$. 16S rRNA oligonucleotide cataloguing (37), however, clearly indicated no relationship to Methanomicrobium mobile. In this contribution we present the $16 \mathrm{~S}$ rRNA catalogue and additional physiological and biochemical data. The results justify a reclassification of Methanomicrobium paynteri DSM 2545. Therefore, we propose to place Methanomicrobium paynteri DSM 2545 within a new genus, Methanolacinia gen. nov., as Methanolacinia paynteri comb. nov. (ex Rivard et al. 1984, 25).

\section{MATERIALS AND METHODS}

Source of organisms and cultivation. Methanomicrobium paynteri DSM 2545, Methanomicrobium mobile DSM 1539, Methanogenium marisnigri DSM 1498, Methanogenium cariaci DSM 1497 and Methanospirillum hungatei DSM 864 were obtained from the Deutsche Sammlung von Mikroorganismen und Zellkulturen GmbH, Mascheroderweg 1b, D-3300 Braunschweig, FRG. Methanoplanus limicola DSM 2279 was a gift of Prof. Dr. K. O. Stetter (Regensburg). Methanobacterium palustre DSM 3108, Methanogenium tationis DSM 2702, Methanogenium thermophilum DSM 2640 and Methanocorpusculum parvum DSM 3823 were isolated in our laboratory and maintained as described (39).

Methanomicrobium paynteri DSM 2545, Methanogenium marisnigri DSM 1498, Methanogenium tationis DSM 2702, Methanogenium cariaci DSM 1497, Methanogenium thermophilum DSM 2640 and Methanoplanus limicola DSM 2279 were grown in medium 3 (1) using the method of Balch et al. (1). Methanobacterium palustre DSM 3108 and Methanospirillum hungatei DSM 864 were grown in medium 1(1). For Methanomicrobium mobile DSM 1539 and Methanocorpusculum parvum DSM 3823 medium 1 was modified as described (42).

To test the substrate spectrum, the $\mathrm{H}_{2} / \mathrm{CO}_{2}$ gas phase of the respective media was replaced by $\mathrm{N}_{2} / \mathrm{CO}_{2}(80: 20 \%, 300 \mathrm{kPa})$ and formate, acetate, methanol, 2-propanol, 2-butanol and cyclopentanol were added from sterile, anaerobic stock solutions $(20 \% \mathrm{w} / \mathrm{v}$ or $\mathrm{v} / \mathrm{v})$ to give a final concentration of $0.5 \%$. All cultures were incubated on a rotary shaker at $100 \mathrm{rpm}$ and at $37^{\circ} \mathrm{C}$, with the exception of Methanogenium thermophilum DSM 2640, which was grown at $55^{\circ} \mathrm{C}$. Mass cultivation was performed in 10- $l$ Braun fermentors (Biostat $\mathrm{V}$ and Biostat $\mathrm{S}$, Braun, Melsungen, FRG) on $\mathrm{H}_{2} / \mathrm{CO}_{2}(80: 20 \%$, v/v, ca. $30 \mathrm{l} / \mathrm{h})$.

For 16S rRNA cataloguing cells of Methanoplanus limicola DSM 2279, Methanolobus tindarius DSM 2278, "Methanolobus siciliae" DSM 3028(33) and "Methanolobus vulcani" DSM 3029 (33) were grown in medium 3(39) with methanol $\left(0.5 \%\right.$ final concentration) at $30^{\circ} \mathrm{C}$ and $100 \mathrm{rpm}$ (Cells kindly provided by Prof.

Dr. K. O. Stetter, University of Regensburg, FRG).

Analyses. Methane, 2-propanol and acetone were analysed by gas 
chromatography (42). Other substrates or products were gas chromatographically determined using a Chromosorb 101 column for separation. The oven temperature was $120^{\circ} \mathrm{C}$ for methanol and ethanol, $140^{\circ} \mathrm{C}$ for 2-butanol and 2-butanone, $180^{\circ} \mathrm{C}$ for 1-propanol, 1-butanol, acetate, 2-pentanol and 2-pentanone, and $195^{\circ} \mathrm{C}$ for cyclopentanol, cyclohexanol, cyclopentanone and cyclohexanone. Detection was by flame ionization at $220^{\circ} \mathrm{C}(45)$.

Sodium dodecylsulfate polyacrylamide gel electrophoresis (SDS-PAGE). SDSsoluble whole cell extracts of Methanomicrobium paynteri were separated on $10 \%$ slab gels and stained either with Coomassie blue for proteins or with the periodateSchiff reagent (PAS-staining) for carbohydrates (14).

Electron microscopy. Micrographs of thin sections or freeze-etched cell preparations were taken on a Philips EM 301 electron microscope at $80 \mathrm{kV}$ as described (15).

Polyamines. Polyamines were determined as described (29).

Analyses of polar lipids-Polar lipid extraction and thin layer chromatography. Polar lipids were extracted from freeze-dried cells using a combination of methods $(3,17,20,43)$. Polar lipids were separated by two-dimensional thin layer chromatography on silica gel (Machery Nagel Art. No. 804023). Following development in chloroform : methanol : water $(65: 25: 4, \mathrm{v} / \mathrm{v})$, in the first direction, and chloroform:methanol:acetic acid:water $(80: 12: 15: 4, \mathrm{v} / \mathrm{v})$, in the second direction, the plates were sprayed with specific spray reagents to detect sugars ( $\alpha$-naphthol and anisaldehyde/sulphuric acid), $\alpha$-glycols (periodate-Schiff), free amino groups (ninhydrin), phosphate (molybdate), quaternary nitrogen (Dragendorff), and primary/secondary amino groups (chlorine/starch-iodide).

Hydrolysis of cells was according to $(8,16)$ and resulted in the release of all ether "core" lipids (Tindall, unpublished). Ether lipids were separated on silica gel thin layers (Machery Nagel Art. No. 804023) developed in hexane: diethyl ether $(4: 1, v / v)$, double development $(34)$ or hexane : diethyl ether : acetic acid $(25: 25: 1$, $\mathrm{v} / \mathrm{v})$ (Tindall, unpublished) for diethers, and diethers and tetraethers, respectively.

$16 S$ rRNA cataloguing. 16S rRNA cataloguing was done according to Stackebrandt et al.(32) and similarity coefficients were calculated as indicated by Fox et al. (5).

Chemical reagents. All chemicals were of analytical grade and were purchased from Merck (Darmstadt, FRG) and Sigma (Munich, FRG). $\gamma^{32}$ P-ATP $(1.073 \times$ $10^{14} \mathrm{~Bq} / \mathrm{mmol}$ ) was obtained from New England Nuclear (NEN, Dreieich, FRG).

\section{RESULTS}

\section{Morphoiogy}

Methanolacinia paynteri DSM 2545 is a pleomorphic microorganism containing an S-layer of hexagonally arranged glycoprotein subunits and was flagellated, although there was no motility (Fig. 1). The center-to-center spacing of the individual glycoprotein subunits was $15.3 \mathrm{~nm}$. Ultrathin sections clearly demonstrated the 


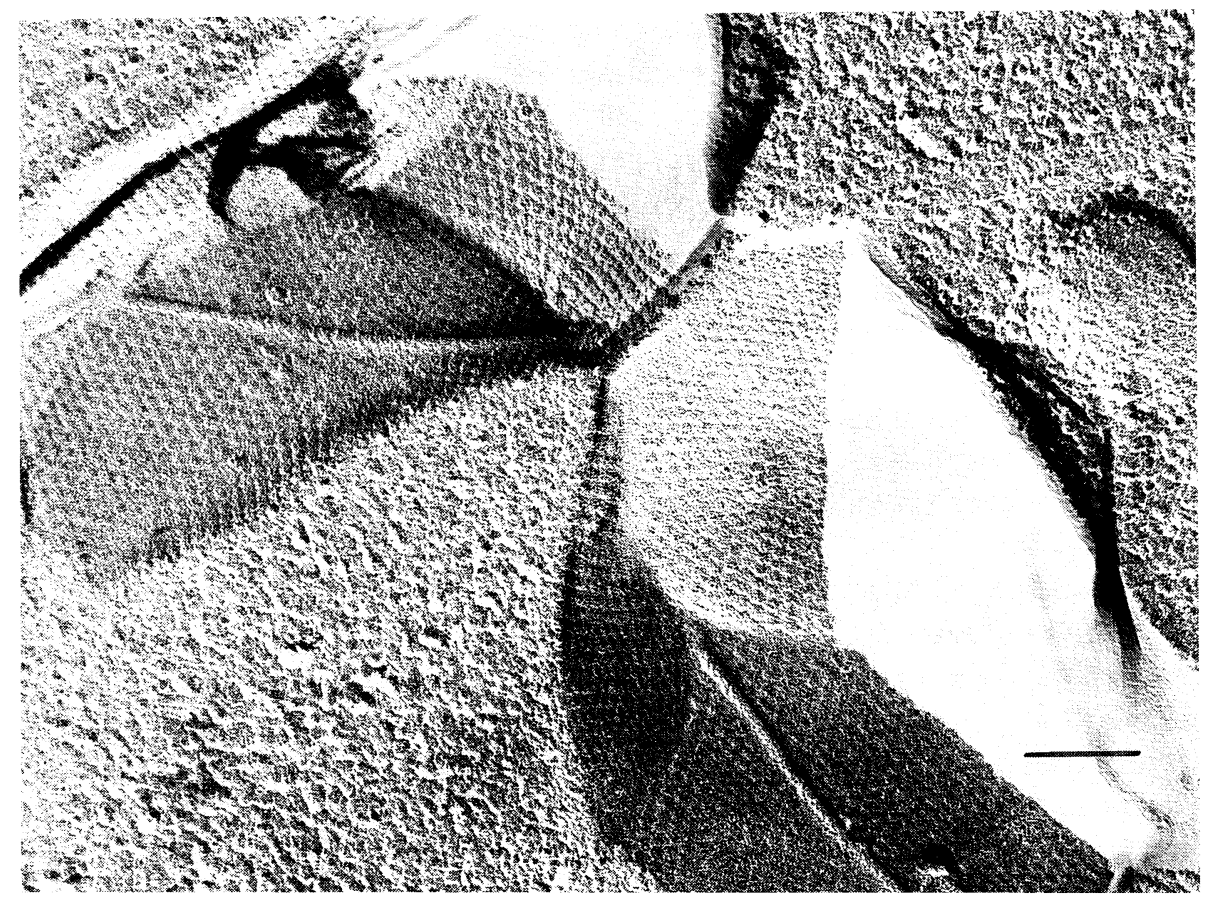

Fig. 1. Electron microphotograph of a freeze-etched preparation of Methanomicrobium paynteri DSM 2545. $\mathrm{Bar}=100 \mathrm{~nm}$.

S-layer as the only shape-determining structural component of the envelope and the absence of other rigid cell wall material (Fig. 2). SDS-PAGE of whole cell extracts, solubilized by $0.1 \%$ SDS solution, revealed a range of cellular proteins, two of which were stainable by the PAS-procedure for carbohydrates. Presumably, the band with an apparent molecular weight of 155,000 represented the S-layer glycoprotein (Fig. 3). The weaker band with $M_{\mathrm{r}} 135,000$ may represent a degradation product or a less glycosylated precursor. In thin sections only one S-layer was visible (Fig. 2).

\section{Substrates}

Methanomicrobium paynteri DSM 2545 was reported to utilize only $\mathrm{H}_{2} / \mathrm{CO}_{2}$ as substrate (24). However, this organism utilized, in addition, 2-propanol, 2-butanol (45) and cyclopentanol (2) as hydrogen donors for the reduction of $\mathrm{CO}_{2}$ to $\mathrm{CH}_{4}$, with concomitant oxidation of the alcohols to the respective ketones (45).

Comparison of the polyamine content of Methanomicrobium paynteri with that of other methanogens

The polyamine patterns of Methanomicrobium paynteri DSM 2545, Methanomicrobium mobile DSM 1539 and of other methanogens was compared (Table 


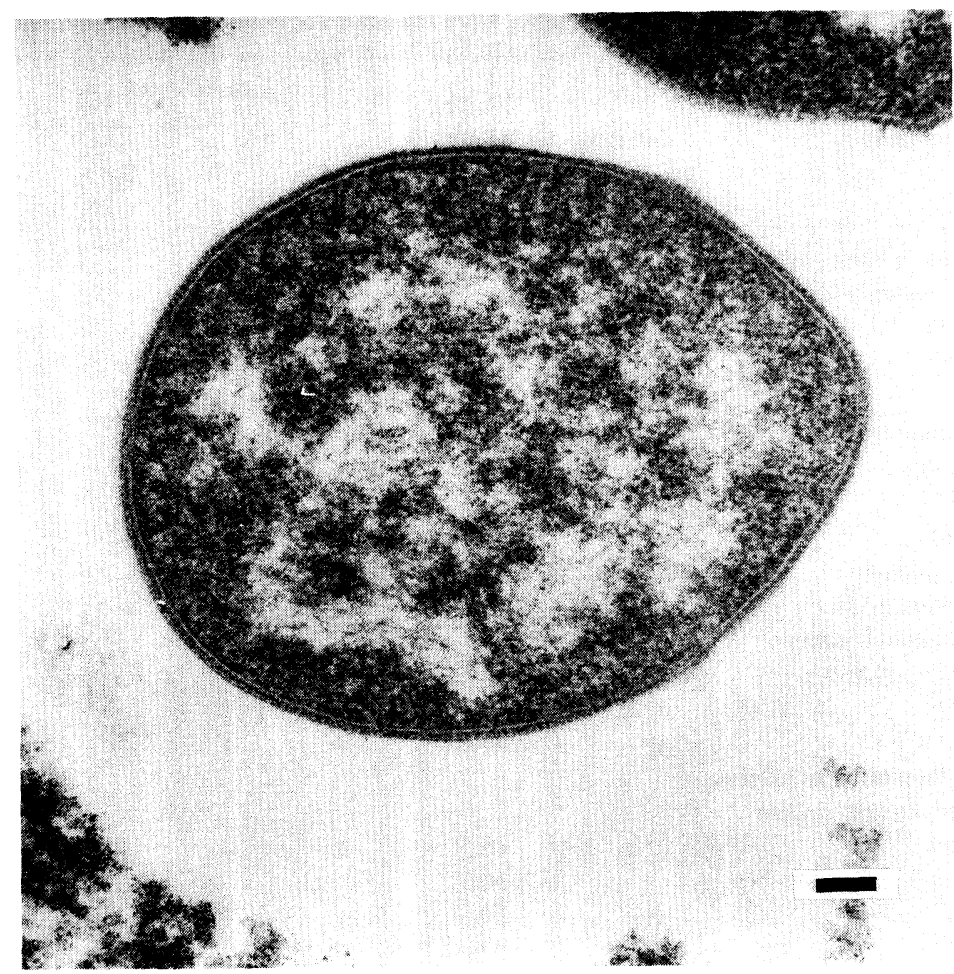

Fig. 2. Electron microphotograph of a thin section of Methanomicrobium paynteri DSM 2545. $\mathrm{Bar}=100 \mathrm{~nm}$.

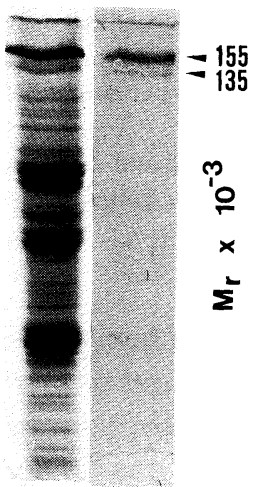

Fig. 3. SDS-PAGE of cell extracts of Methanomicrobium paynteri DSM 2545. Coomassie blue staining (left lane), PAS-staining (right lane).

1). While Methanomicrobium mobile DSM 1539 contained 1,3-diaminopropane, and some sym-homospermidine and spermine as polyamines, Methanomicrobium paynteri DSM 2545 did not contain 1,3-diaminopropane. In contrast, Methanomi- 
Table 1. Characteristic features of coccoid members of the

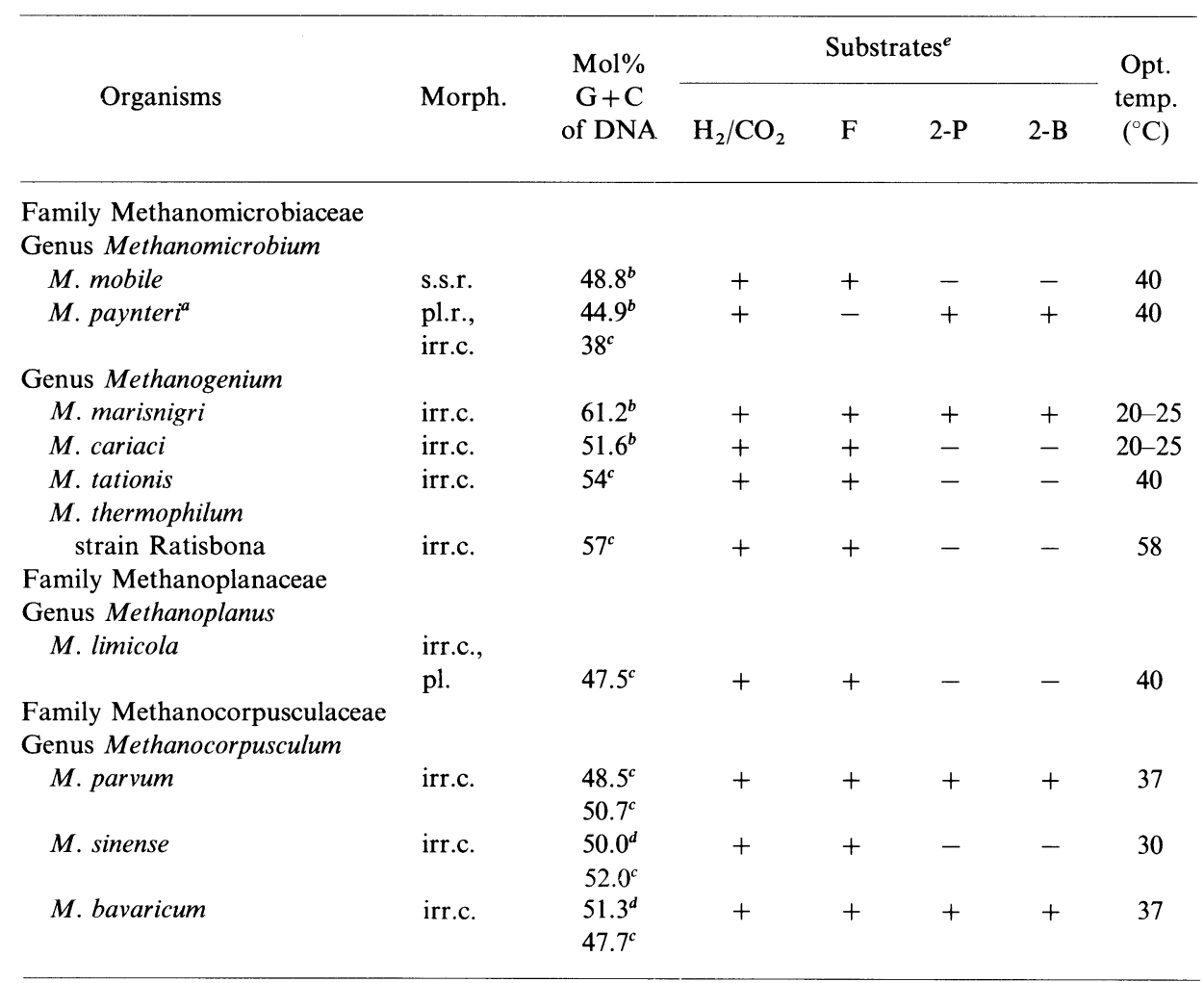

a Renamed Methanolacinia paynteri as a result of this study.

b $\quad \mathrm{Mol} \% \mathrm{G}+\mathrm{C}$ of DNA calculated from buoyant density (bd).

c $\mathrm{Mol} \% \mathrm{G}+\mathrm{C}$ of DNA determined from thermal denaturation $\left(T_{\mathrm{m}}\right)$.

${ }^{d} \mathrm{Mol} \% \mathrm{G}+\mathrm{C}$ of DNA analyzed by high performance liquid chromatography (HPLC) of digested DNA.

e Substrates extended to 2-propanol $/ \mathrm{CO}_{2}$ and 2-butanol $/ \mathrm{CO}_{2}$ utilization (42-45; this paper). All strains presented in this list are unable to utilize acetate, methanol, ethanol, mono-, di- and trimethylamine.

crobium paynteri DSM 2545 contained high amounts of putrescine and spermidine, which were only detected in trace amounts in Methanomicrobium mobile DSM 1539. A significantly higher putrescine content than in Methanomicrobium mobile DSM 1539 was found in all other species of the family Methanomicrobiaceae that were tested. High amounts of 1,3-diaminopropane were only found in Methanocorpusculum species (52-75 $\mu \mathrm{mol} / \mathrm{g}$ dry weight), whereas Methanomicrobium mobile DSM 1539 contained $8 \mu \mathrm{mol} / \mathrm{g}$ dry weight, and only trace amounts of 1,3-diaminopropane were found in Methanomicrobium paynteri DSM 2545 and the other investigated methanogens (Table 1). 
Methanomicrobiaceae, Methanoplanaceae and Methanocorpusculaceae.

\begin{tabular}{|c|c|c|c|c|c|c|c|c|c|c|}
\hline \multicolumn{3}{|c|}{ S-layer ${ }^{f}$} & \multicolumn{7}{|c|}{ Polyamines $^{g}$} & \multirow{2}{*}{ References } \\
\hline Sym. & $\mathrm{c} / \mathrm{c}$ & $\begin{array}{c}M_{\mathrm{r}} \\
(\mathrm{kD})\end{array}$ & DAP & PUT & NSPD & SPD & HSPD & NSPM & SPM & \\
\hline
\end{tabular}

\begin{tabular}{|c|c|c|c|c|c|c|c|c|c|c|}
\hline $\mathbf{P}$ & - & - & 8.4 & 0.4 & 一 & 0.3 & 1.0 & - & 0.9 & $(23,30,31$, this paper $)$ \\
\hline $\mathrm{H}$ & 15.3 & 155 & - & 10.8 & - & 15.6 & - & - & 0.1 & $(24,25,45$, this paper $)$ \\
\hline $\mathrm{H}$ & - & 138 & nd & 21.8 & 一 & - & 9.6 & - & 0.3 & $(9,27,45)$ \\
\hline $\mathrm{H}$ & 14.0 & 117 & 0.04 & 11.6 & - & 0.02 & 0.07 & - & 0.04 & $(27,45$, this paper $)$ \\
\hline $\mathrm{H}$ & - & 120 & - & 56.5 & - & 0.1 & 7.9 & - & 1.3 & $(40,45$, this paper $)$ \\
\hline $\mathbf{H}$ & - & 130 & 0.03 & 5.0 & - & 0.2 & 15.5 & - & 2.7 & $(41,45$, this paper $)$ \\
\hline $\mathrm{H}$ & 14.0 & 143 & nd & 3.5 & - & 0.05 & 4.5 & - & 0.1 & $(9,38,45)$ \\
\hline $\mathrm{H}$ & 14.3 & 90 & 51.6 & 14.8 & - & 0.28 & - & - & 0.23 & $(30,42,44,45)$ \\
\hline $\mathrm{H}$ & 15.8 & 92 & 75.0 & 7.7 & - & 0.20 & - & - & 0.35 & $(44)$ \\
\hline $\mathrm{H}$ & 16.0 & 94 & 53.5 & 7.2 & - & 0.26 & - & - & 1.35 & $(44)$ \\
\hline
\end{tabular}

$f$ S-layer geometry: $\mathrm{P}=$ periodic structures not further characterized (e.g. evidence from thin sections), $\mathrm{H}=$ hexagonal arrangement of $\mathrm{S}$-layer proteins, $\mathrm{c} / \mathrm{c}=$ center-to-center spacings of $\mathrm{S}$-layer proteins $(\mathrm{nm}), M_{\mathrm{r}}=$ apparent molecular weight of S-layer proteins (kD).

${ }_{g} \mu \mathrm{mol} / \mathrm{g}$ dry weight of cells; $-=$ below the detection limit of $0.03 \mu \mathrm{mol} / \mathrm{g}$ dry weight. $\mathrm{DAP}=1,3$-diaminopropane, $\mathrm{PUT}=$ putrescine, $\mathrm{NSPD}=$ norspermidine, $\mathrm{SPD}=$ spermidine, $\mathrm{HSPD}=$ sym-homospermidine, NSPM = norspermine, SPM = spermine.

Abbreviations: s.s.r. = small short rod; pl.r. = pleomorphic rod; irr.c. = irregular coccus; pl. = plateshaped; $\mathrm{F}=$ formate; $2-\mathrm{P}=2$-propanol $/ \mathrm{CO}_{2} ; 2-\mathrm{B}=2$-butanol $/ \mathrm{CO}_{2} ; \mathrm{nd}=$ not determined.

\section{Lipids}

Analysis of the lipid fraction of Methanomicrobium mobile DSM 1539, Methanomicrobium paynteri DSM 2545, and Methanogenium cariaci DSM 1497 revealed the presence of ether lipids (Figs. 4a-d and 5). The three organisms contained both diether and tetraether "core" lipids. On the basis of TLC $R f$ values the major ether lipids present were di-O-phythanyl-glycerol diethers and dibiphythanyl-glycerol tetraethers (Fig. 5). No conclusive evidence was found for the presence of other ether lipids in Methanomicrobium mobile DSM 1539 as reported previously (6). The lipid material with $R f$ values intermediate between the diether and tetraether lipids in this strain showed staining behavior typical of unsaturated 

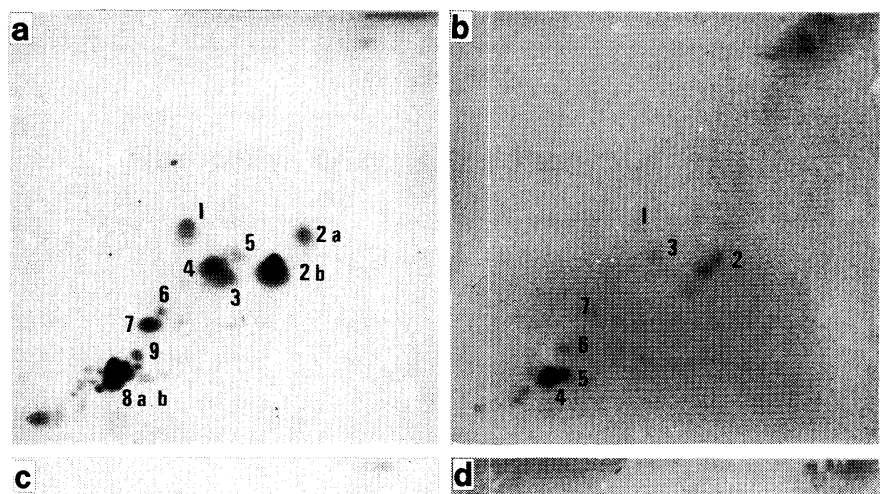

C

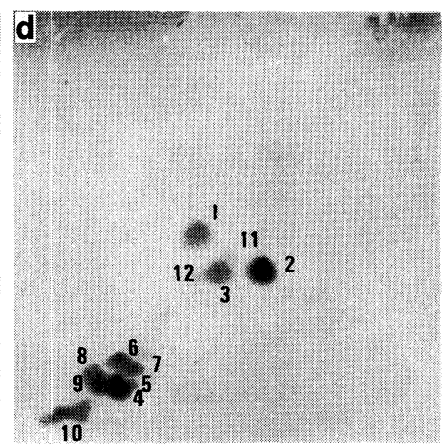

Fig. 4a-d. Two-dimensional thin layer chromatography of the polar lipids of Methanospirillum hungatei DSM 864 (a), Methanomicrobium mobile DSM 1539 (b), Methanomicrobium paynteri DSM 2545 (c), and Methanogenium cariaci DSM 1497 (d). Chromatography conditions are as described in MATERIALS AND METHODS. Key to staining reactions and identity of lipids in accompanying tables.

material, and its identity as further fully saturated isoprenoid ether lipid material could not be confirmed. The ether "core" lipid composition of the three strains was essentially similar, although the presence of other lipid material in the hydrolyzed lipid fraction may be indicative of significant differences between Methanomicrobium mobile DSM 1539 and Methanomicrobium paynteri DSM 2545 (Fig. 4a, b).

To adequately identify the polar lipids in Methanomicrobium mobile DSM 1539, Methanomicrobium paynteri DSM 2545 and Methanogenium cariaci DSM 1497, standard lipid mixtures or isolated lipid standards were used from Halobacterium cutirubrum (NRC 34002), Methanospirillum hungatei DSM 864, and Methanobacterium palustre DSM 3108. The polar lipid patterns of the two Methanomicrobium species, Methanogenium cariaci DSM 1497 and the reference strain of Methanospirillum hungatei 864 are illustrated in Fig. $4 a-d$. The staining reactions and probable identity of the various lipids are listed in Table 2.

In common with lipid patterns of other methanogens studied previously, all four species showed complex patterns due to the presence of di- and tetraether derivatives with one and two different polar head groups, respectively. In all four 
Table. 2 Staining reactions of the various lipids of Methanomicrobium paynteri, Methanomicrobium mobile, Methanogenium cariaci and Methanospirillum hungatei.

\begin{tabular}{|c|c|c|c|c|c|c|c|c|}
\hline \multirow{2}{*}{ Strain } & & \multicolumn{6}{|c|}{ Lipid stain } & \multirow{2}{*}{ Identity } \\
\hline & & $\mathrm{PO}_{4}$ & $\mathrm{NH}_{2}$ & $\begin{array}{l}\mathrm{NH}_{2} / \\
\mathrm{NH}\end{array}$ & $\begin{array}{l}\text { Drag- } \\
\text { endorff }\end{array}$ & $\begin{array}{c}\alpha- \\
\text { glycol }\end{array}$ & Sugars & \\
\hline \multirow[t]{12}{*}{ Methanomicrobium paynteri $^{a}$} & 1 & + & - & - & - & + & - & PG \\
\hline & 2 & - & - & - & - & + & + & DGD \\
\hline & 3 & + & + & + & - & + & - & PPAD? \\
\hline & 4 & + & - & - & - & + & + & $\mathrm{PG}+\mathrm{DGD}$ \\
\hline & 5 & + & + & + & - & + & + & PPAD + DGD \\
\hline & 6 & + & - & - & + & + & - & PPTAD \\
\hline & 7 & + & - & - & - & + & + & PGL \\
\hline & 8 & + & - & - & - & - & - & PL \\
\hline & 9 & + & - & - & + & + & + & PPTAD + DGD \\
\hline & 10 & + & - & - & - & + & + & PGL \\
\hline & 11 & + & - & - & - & - & - & PL \\
\hline & 12 & + & - & - & - & - & - & PL \\
\hline \multirow[t]{7}{*}{ Methanomicrobium mobile } & 1 & + & - & - & - & + & - & PG (trace) \\
\hline & 2 & - & - & - & - & + & + & DGDs \\
\hline & 3 & + & + & + & - & + & - & PPAD? \\
\hline & 4 & + & - & - & - & + & + & PG + DGD \\
\hline & 5 & + & + & + & - & + & + & PPAD + DGD? \\
\hline & 6 & + & - & - & - & + & + & PGL \\
\hline & 7 & + & - & - & + & + & - & PPTAD \\
\hline \multirow[t]{12}{*}{ Methanogenium cariaci } & 1 & + & - & - & - & + & - & PG \\
\hline & 2 & - & - & - & - & + & + & DGD \\
\hline & 3 & + & + & + & - & + & - & PPAD? \\
\hline & 4 & + & - & - & - & + & + & $P G+D G D$ \\
\hline & 5 & + & + & + & - & + & + & PPAD + DGD \\
\hline & 6 & + & - & - & - & + & + & PGL \\
\hline & 7 & + & + & + & - & + & + & $\mathrm{NH}_{2} \mathrm{PGL}$ \\
\hline & 8 & + & + & + & - & + & + & $\mathrm{NH}_{2} \mathrm{PGL}$ \\
\hline & 9 & + & - & - & + & + & + & PPTAD + DGD \\
\hline & 10 & + & - & - & - & + & + & PGL \\
\hline & 11 & + & $?$ & $?$ & $?$ & $?$ & - & PGL \\
\hline & 12 & + & - & - & $?$ & $?$ & - & PGL \\
\hline \multirow[t]{9}{*}{ Methanospirillum hungatei } & 1 & + & - & - & - & + & - & PG \\
\hline & $2 a, b$ & - & - & - & - & + & + & DGDs \\
\hline & 3 & + & + & + & - & + & - & PPAD? \\
\hline & 4 & + & - & - & + & + & - & PPDAD \\
\hline & 5 & + & - & + & - & + & - & PGL \\
\hline & 6 & + & - & - & - & + & + & PGL \\
\hline & 7 & + & - & - & + & + & - & PPTAD \\
\hline & $8 \mathrm{a}, \mathrm{b}$ & + & - & - & - & + & + & PG + DGDs \\
\hline & 9 & + & - & + & - & + & - & PGL \\
\hline
\end{tabular}

a Now reclassified as Methanolacinia paynteri.

Abbreviations: $\mathrm{PG}=$ phosphatidyl glycerol; $\mathrm{DGD}=$ diglycosyl diether; $\mathrm{PL}=$ phospholipid; $\mathrm{PGL}=$ phosphoglycolipid; $\mathrm{NH}_{2} \mathrm{PGL}=$ amino-phosphoglycolipid; $\mathrm{PPAD}=$ phospho-pentanetetrol amino diether; PPDAD = phospho-pentanetetrol dimethylamino diether; PPTAD = phospho-pentanetetrol trimethylamino diether. 


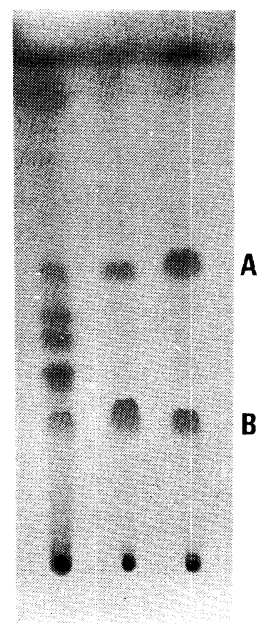

Fig. 5. Thin layer chromatography of the acid methanolysates of (from left to right) Methanomicrobium mobile DSM 1539, Methanomicrobium paynteri DSM 2545, and Methanogenium cariaci DSM 1497. Solvent $=$ hexane $:$ diethyl ether $:$ acetic acid $(25: 25: 1$, v/v). A, 2,3-di-O-phythanyl-sn-glycerol; B, biphythanyl-glycerol ether.

species the presence of diglycosyl ether lipids was detected. In the case of Methanospirillum hungatei DSM 864 there were two different diglycosyl diethers, consistent with previous detailed structural analyses (13). A number of glycolipids containing other functional groups together with a range of phospholipids also characterized the four species studied. There was a phospholipid with an $R f$ value identical with authentic phosphatidylglycerol diether (PG) from Halobacterium cutirubrum NRC 34002 in significant amounts in Methanomicrobium paynteri DSM 2545, Methanogenium cariaci DSM 1497 and Methanospirillum hungatei DSM 864, whereas only trace amounts were found in Methanomicrobium mobile DSM 1539. In previous surveys $(6,10)$, this lipid was not mentioned. Kushwaha et al. (13) reported the presence of phosphoglycerol polar head groups in Methanospirillum hungatei. A number of phospholipids were detectable in all four species (Table 2). Two of these phospholipids were common to all four species. One gave a positive reaction with the phosphate, quarternary nitrogen and $\alpha$-glycol spray reagents, and had an $R f$ value similar to that of phosphatidyl choline (PC). However, the presence of $\alpha$-glycol groups in the lipid suggests that this is not an ether derivative of PC. Furthermore this lipid was quite easily hydrolysed under both alkaline and acid conditions, in contrast to the reported stability of the ether derivative of PC (11). Recent studies have shown that Methanospirillum hungatei DSM 864 does indeed contain such an unusual lipid (4), in which the choline molecule is further derivatised with a glycerol group, resulting in the formation of a trimethylaminopentanetetrol molecule. The $R f$ value of the presumptive phosphatidyltrimethylaminopentanetetrol diether (PPTAD) in Methanospirillum hungatei DSM 864 is consistent with re- 
ported $R f$ values, and indicates that this lipid is present in all four species, albeit in trace amounts in Methanogenium cariaci DSM 1497. The second unusual lipid, common to the four species, gave a positive reaction with the phosphate, amino, and $\alpha$-glycol spray reagents. The $R f$ value was somewhat less than the authentic phosphatidylethanolamine ether derivative (PE) from Methanobacterium palustre DSM 3108. The presence of $\alpha$-glycols suggests a polyol structure in an aminophospholipid. The acid and alkali lability of this compound was also in stark contrast to the stability of the ether derivatives of PE and phosphatidyl serine (PS) (18, 21; Tindall, unpublished). There are no reports of such a compound in other methanogenic bacteria, although Ferrante et al.(4) have isolated a dimethylaminopentanetetrol from Methanospirillum hungatei DSM 864 with an $R f$ value close to that of this compound (identified as lipid 4 in this study, Fig. 4). Comparisons with eubacterial lipids show that ethanolamine may also be found in which one (monomethylethanolamine) or two (dimethylethanolamine) of the amino hydrogens are replaced by methyl groups $(8)$. This lipid may represent the demethylated equivalent of PPTAD, phosphatidylaminopentanetetrol diether (PPAD). Among the phosphoglycolipids, the predominant compound in all four species gave staining reactions consistent with the presence of sugars, phosphate, and a terminal $\alpha$-glycol group. No evidence was found for the presence of nitrogen in this lipid, although other $\alpha$-glycol phosphoglycolipids with free amino or a quarternary nitrogen group were detected. Hydrolysis of the phosphate groups resulted in the release of diglycosyl ethers, indicating that all sugar-containing lipids were diglycosyl ethers. This suggested that the major phosphoglycolipid present in these organisms is a diglycosyl phosphatidyl glycerol ether, as reported previously in Methanospirillum hungatei DSM 864. Interestingly the lipids of Methanogenium cariaci DSM 1497 contained several other phosphoglycolipids, several of which were also amino positive, and one of which gave a positive reaction for quarternary nitrogen compounds, providing support for the conclusion that the phospho polar head group in the major diglycosyl phospholipid was indeed phosphoglycerol as reported previously(13). It is clear from the evidence presented here that the important lipids present in these representatives of the family Methanomicrobiaceae are the ether derivatives of PG, presumptive PPAD, PPTAD, and diglycosyl phosphatidyl glycerol. However, there are distinct differences between the four species examined in the nature of the other polar lipids present, and these seem to reflect differences at the species or genus level. At present too little information is available on the detailed structures of the polar lipids to permit a clear separation of the genera based on polar lipid patterns as proposed for the family Halobacteriaceae $(12,19,28,35)$. The data presented here support the differentiation between Methanomicrobium mobile DSM 1539 and Methanomicrobium paynteri DSM 2545, and indicate the chemotaxonomic differences between all four species examined in this study.

Consistent with previous studies no evidence was found for the presence of respiratory lipoquinones in any of the methanogenic strains examined. 
16S rRNA oligonucleotide signature sequence

The 16S rRNA oligonucleotide catalogue of Methanomicrobium paynteri DSM 2545 is listed in Table 3. Also indicated is the presence of these oligonucleotides in catalogues of members of the order Methanomicrobiales, whose catalogues have been published previously, i.e. Methanomicrobium mobile DSM 1539, Methanogenium cariaci DSM 1497, Methanogenium marisnigri DSM 1498, Methanospirillum hungatei DSM 864, Methanosarcina barkeri DSM 800 (1), Methanothrix soehngenii DSM 2139(7), and Methanocorpusculum parvum DSM 3823 (42) or which are unpublished (Methanolobus tindarius DSM 2278, "Methanolobus siciliae" DSM 3028, "Methanolobus vulcani" DSM 3029 and Methanoplanus limicola DSM 2279). Similarity coefficients ( $S_{\mathrm{AB}}$-values) for these organisms are compiled in Table 4. The two species of Methanomicrobium do not show the highest value as expected

Table 3. Occurrence of oligonucleotide signature sequences in the catalogue of the $16 \mathrm{~S}$ rRNA oligonucleotide sequences of different species of the Methanomicrobiales.

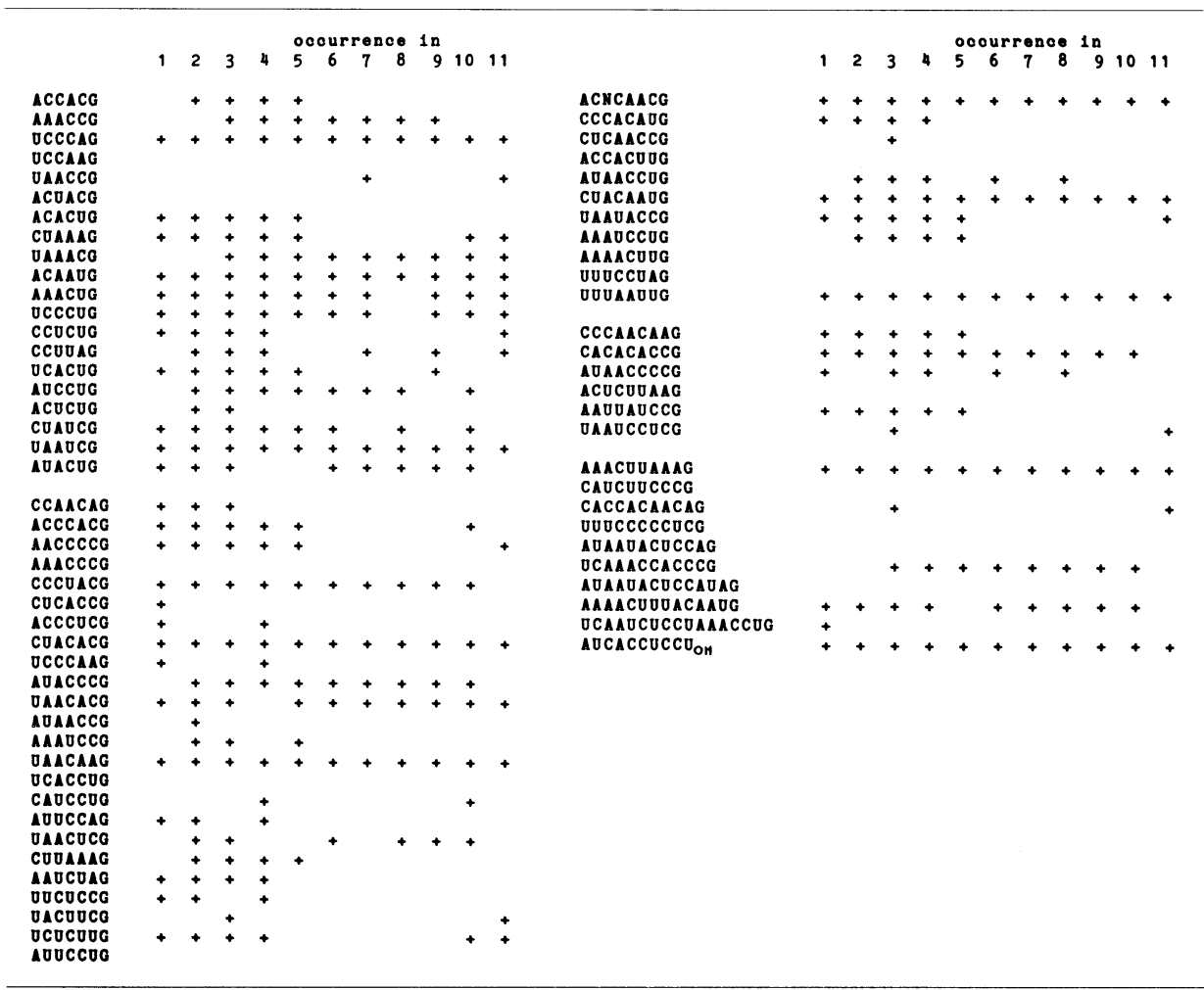

1, Methanomicrobium mobile DSM 1539; 2, Methanogenium cariaci DSM 1497; 3, Methanogenium marisnigri DSM 1498; 4, Methanoplanus limicola DSM 2279; 5, Methanospirillum hungatei DSM 864; 6, Methanosarcina barkeri DSM 800; 7, Methanolobus tindarius DSM 2278; 8, "Methanolobus siciliae" DSM 3028; 9, "Methanolobus vulcani" DSM 3029; 10, Methanothrix soehngenii DSM 2139; 11, Methanocorpusculum parvum DSM 3823. 


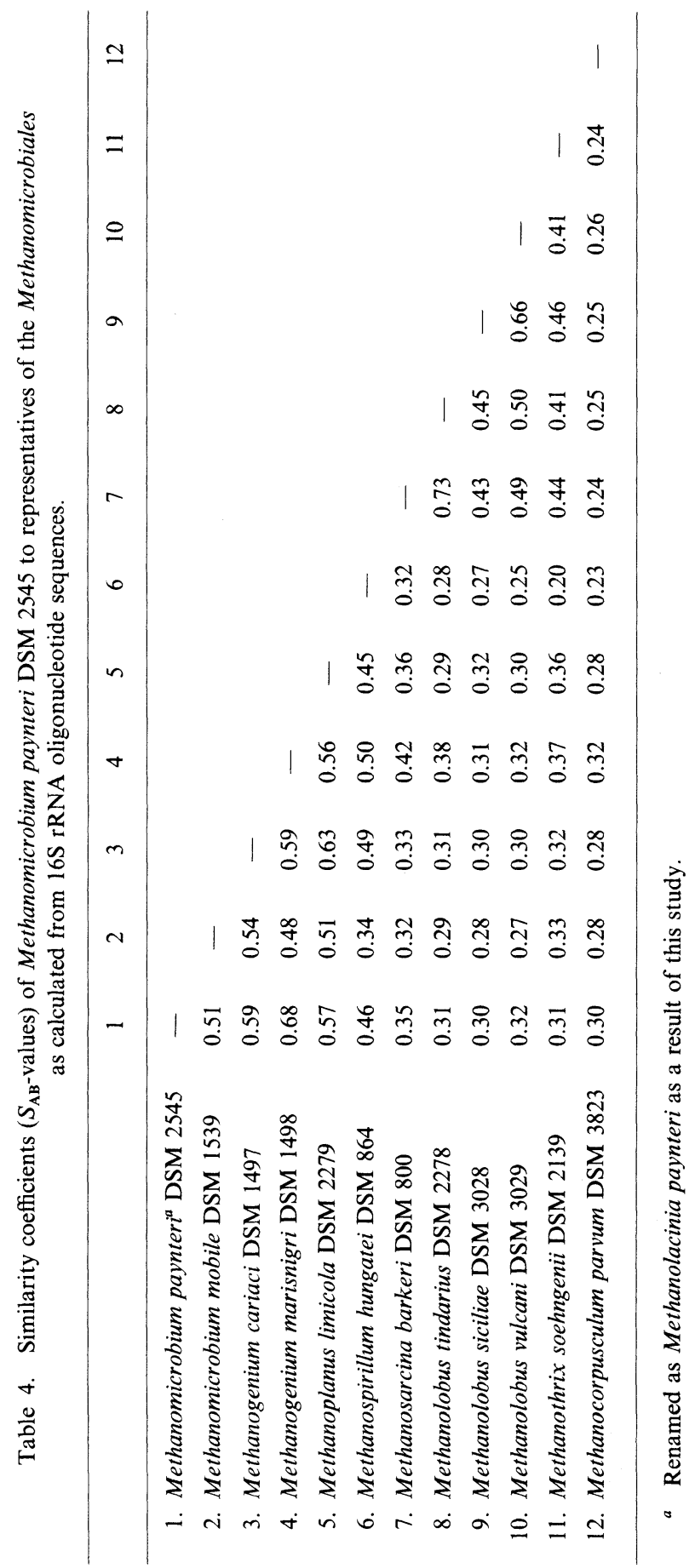




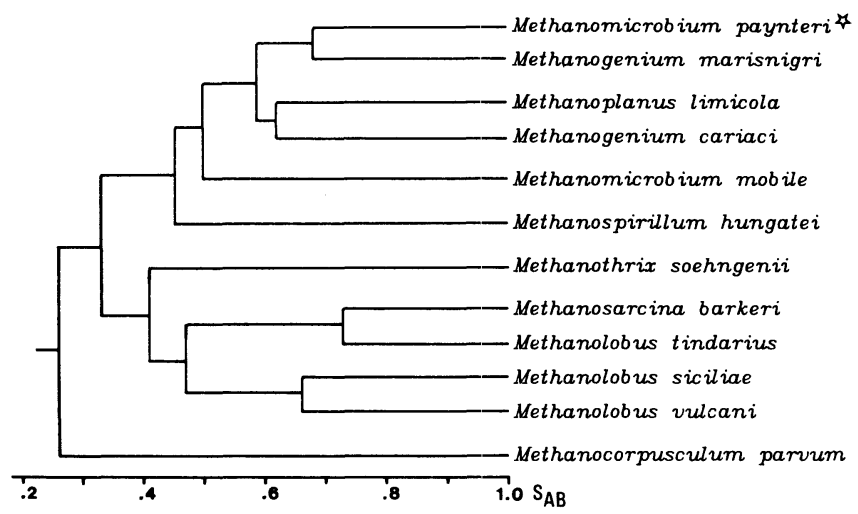

Fig. 6. Dendrogram indicating the phylogenetic position of Methanomicrobium paynteri DSM 2545 within the order Methanomicrobiales.

from their allocation to the same genus. Methanomicrobium paynteri DSM 2545 is more closely related to Methanogenium marisnigri DSM 1498 (0.68), whose relationship to Methanogenium cariaci DSM 1497 is unexpectedly low. The latter species, on the other hand, shows the highest degree of relatedness to Methanoplanus limicola DSM 2279. All members of the family Methanomicrobiaceae are clearly separated from those of Methanosarcinaceae and from Methanocorpusculum parvum DSM 3823. Figure 6 exhibits these relationships in a dendrogram.

\section{DISCUSSION}

Rivard et al. $(24,25)$ described a new mesophilic marine methanogen, which they named Methanomicrobium paynteri DSM 2545. However, a comparison of the features of Methanomicrobium mobile DSM 1539 and Methanomicrobium paynteri, presented in this study, revealed significant differences between the two species. As outlined in Table 1, Methanomicrobium paynteri does not share more common characteristics with $M$. mobile than with other members of the genera of the family Methanomicrobiaceae. Analyses of the polar lipid patterns of Methanomicrobium mobile DSM 1539, Methanomicrobium paynteri DSM 2545, Methanospirillum hungatei DSM 864 and Methanogenium cariaci DSM 1497 showed that they had basically four common lipids, PG, presumptive PPAD, PPTAD, and a diglycosyl ether. There are, however, significant differences between the four species. Therefore, the polar lipid data presented here support the proposed removal of Methanomicrobium paynteri DSM 2545 from the genus Methanomicrobium.

Besides phenotypic characteristics, the two Methanomicrobium species are also different at the genotypic level including base composition of DNA and 16S rRNA. For these reasons Methanomicrobium paynteri DSM 2545 should be excluded from the genus Methanomicrobium. Using the phylogenetic branching pattern (Fig. 6) as a guideline for taxonomic changes as orginally devised by Balch et al.(1), two 
alternative proposals could be made. Firstly, all members of the Methanogenium-Methanoplanus limicola DSM 2279-Methanomicrobium paynteri DSM 2545 cluster belong to one genus, namely Methanomicrobium (37). This genus, however, would combine organisms with marked differences in morphology, mol\% G+C of DNA (38-61 mol\% $\mathrm{G}+\mathrm{C})$ and polyamine content (9; the study), thus deteriorating rather than improving its coherence. Secondly, the genus Methanogenium is split into two genera, one represented by the type species Methanogenium cariaci DSM 1497, the other by Methanogenium marisnigri DSM 1498 and possibly, as based on physiological criteria and a considerably higher GC-content of the DNA, Methanogenium thermophilum DSM 2373(26), and Methanogenium bourgense DSM 3045(22). In this instance, Methanoplanus would keep its generic status and Methanomicrobium paynteri DSM 2545 has to be described as the type strain of a new genus. Based on 16S rRNA analysis Methanoplanus limicola DSM 2279 appears to be quite clearly located within the family Methanomicrobiaceae (Fig. 6), which has been described as a member of the family Methanoplanaceae $(35,36,38)$.

To describe genera which are phylogenetically and phenotypically coherent and distinct from related taxa we favor proposal two. Although it is too early to make formal taxonomic changes for the genus Methanogenium (only 2 of 8 described species have been analyzed by phylogenetic methods so far), we propose to classify Methanomicrobium paynteri DSM 2545 as Methanolacinia paynteri gen. nov., comb. nov.

The formal description of Methanolacinia paynteri is based on the description of Methanomicrobium paynteri by Rivard et al. $(24,25)$ supplemented with additional information (see Tables 1-4).

Formal description of Methanolacinia paynteri gen. nov., comb. nov.

Order: Methanomicrobiales (Balch et al. 1979, 1)

Family: Methanomicrobiaceae (Balch et al. 1979, 1)

Genus: Methanolacinia gen. nov., Zellner and Winter

Species: Methanolacinia paynteri comb. nov., Zellner and Winter (ex Rivard et al. 1984, 24, 25)

Methanolacinia, Me.tha.no.la.ci.ni.a, modern chem. comb. form. Methanorelating to methane; M. L. fem. lacinia, a lobe, to indicate the irregular pleomorphological shape of the organism. Methanolacinia paynteri comb. nov. paynter. i, M. L. paynteri to give honour to M. J. B. Paynter.

The description of Methanolacinia paynteri gen. nov., comb. nov. is that given by Rivard et al. $(24,25)$ for Methanomicrobium paynteri:

The cells are Gram-negative, irregular rods that occur singly without filaments, 0.6 by 1.5 to $2.5 \mu \mathrm{m}$ in size; they undergo a morphological change to a coccoid shape during substrate deprivation and remain viable at room temperature for months. Colonies in agar are off-white and circular with entire edges. Only hydrogen-carbon dioxide served as a growth substrate. Neither growth nor methane production was 
detected after 5 weeks when this substrate was replaced by ethanol, methanol, formate, acetate, propionate, pyruvate, monomethylamine, dimethylamine, or trimethylamine, glutamate or glucose. The organism can tolerate a variety of organic secondary buffers. The organism does not require yeast extract of Trypticase, but does require acetate.

The original description is extended as follows:

Pleomorphological, highly irregular coccoid to lobe-shaped cells, about $1.5-2.0 \mu \mathrm{m}$ in diameter, usually occurring singly. Flagellated, but only weakly motile or non-motile. Cell envelope consisting of a hexagonally arranged S-layer with a glycoprotein of $M_{\mathrm{r}}$ of 155,000 and a lattice constant of $15.3 \mathrm{~nm}$.

Strictly anaerobic and chemoorganotrophic. Methane produced from $\mathrm{H}_{2} / \mathrm{CO}_{2}$, 2-propanol $/ \mathrm{CO}_{2}$, 2-butanol $/ \mathrm{CO}_{2}$, and cyclopentanol $/ \mathrm{CO}_{2}$. No growth or methane production detected on acetate, methylamines, ethanol, 1-propanol, 1-butanol and cyclohexanol.

Polar lipids consist of di- and tetraether lipids, and include phosphatidyl glycerol diether (PG), phosphatidyltrimethylaminopentanetetrol diether (PPTAD), diglycosyldiether, presumptive phosphatidylaminopentanetetrol diether (PPAD) and the corresponding phosphoglycolipid ethers. Putrescine and spermidine are the only polyamines.

$\mathrm{Mol} \% \mathrm{G}+\mathrm{C}$ of DNA is $44(\mathrm{bd}$; from 24$)$ and $38\left(T_{\mathrm{m}}\right)$.

We thank Prof. Dr. Uwe B. Sleytr (Vienna, Austria) for valuable discussions.

\section{REFERENCES}

1) Balch, W. E., Fox, G, E., Magrum, L. J., Woese, C. R., and Wolfe, R. S., Methanogens: Reevaluation of a unique biological group. Microbiol. Rev., 43, 260-296 (1979).

2) Bleicher, K., Zellner, G., and Winter, J., Growth of methanogens on cyclopentanol/ $\mathrm{CO}_{2}$ and specificity of alcohol dehydrogenase. FEMS Microbiol. Lett., 59, 307-312 (1989).

3) Bligh, E. G. and Dyer, W. J., A rapid method of lipid extraction and purification. Cain J. Biochem. Physiol., 37, 911-917 (1959).

4) Ferrante, G., Eikel, I., and Sprott, G. D., Structures of diether lipids of Methanospirillum hungatei containing novel head groups $N, N$-dimethylamino- and $N, N, N$,-trimethylaminopentanetetrol. Biochim. Biophys. Acta, 921, 281-291 (1987).

5) Fox, G. E., Peckman, K. J., and Woese, C. R., Comparative cataloguing of 16S ribosomal ribonucleic acid: Molecular approach to prokaryotic systematics. Int. J. Syst. Bacteriol., 27, 44-57 (1977).

6) Grant, W. D., Pinch, G., Harris, J. E., De Rosa, M., and Gambacorta, A., Polar lipids in methanogen taxonomy. J. Gen. Microbiol., 131, 3277-3286 (1985).

7) Huser, B. A., Wuhrmann, K., and Zehnder, A. J. B., Methanothrix soehngenii gen. nov., spec. nov., a new acetotrophic, non-hydrogen oxidizing methane bacterium. Arch. Microbiol., 132, 1-9 (1982).

8) Kates, M., Techniques of Lipidology: Isolation, Analysis, and Identification of Lipids. 2nd ed., Elsevier, Amsterdam, New York, Oxford (1986).

9) Kneifel, H., Stetter, K. O., Andreesen, J. R., Wiegel, J., König, H., and Schoberth, S. M., 
Distribution of polyamines in representative species of archaebacteria. Syst. Appl. Microbiol., 7, 241-245 (1986).

10) Koga, Y., Ohga, M., Nishihara, M., and Morii, H., Distribution of a diphythanyl ether analog of phosphatidylserine and an ethanolamine containing tetraether lipid in methanogenic bacteria. Syst. Appl. Microbiol., 9, 176-182 (1987).

11) Kumar, R., Weintraub, S. T., and Hanahan, D. J., Differential susceptibility of mono- and di- $O$-alkyl ether phosphoglycerides to acetolysis. J. Lipid Res., 24, 930-937 (1983).

12) Kushwaha, S. C., Juez-Perez, G., Rodriguez-Valera, F., Kates, M., and Kushner, D. J., Survey of lipids of a new group of extremely halophilic bacteria from salt ponds in Spain. Can. J. Microbiol., 28, 1365-1372 (1982).

13) Kushwaha, S. C., Kates, M., Sprott, G. D., and Smith, I. C. P., Novel polar lipids from the methanogen Methanospirillum hungatei GP1. Biochim. Biophys. Acta, 664, 156-173 (1981).

14) Messner, P., Hollaus, F., and Sleytr, U. B., Paracrystalline cell wall surface layers of different Bacillus stearothermophilus strains. Int. J. Syst. Bacteriol., 34, 202-210 (1984).

15) Messner, P., Pum, D., Sára, M., Stetter, K. O., and Sleytr, U. B., Ultrastructure of the cell envelope of the archaebacteria Thermoproteus tenax and Thermoproteus neutrophilus. J. Bacteriol., 166, 1046-1054 (1986).

16) Minnikin, D. E., Alashamaony, L., and Goodfellow, M., Differentiation of Mycobacterium, Nocardia, and related taxa by thin layer chromatography analysis of whole-organism methanolysates. J. Gen. Microbiol., 88, 200-204 (1975).

17) Minnikin, D. E., Collins, M. D., and Goodfellow, M., Fatty acid and polar lipid composition in the classification of Cellulomonas, Oerskovia, and related taxa. J. Appl. Bacteriol., 47, 87-95 (1979).

18) Morii, H., Nishihara, M., Ohga, M., and Koga, Y., A diphythanyl ether analogue of phosphatidyl serine from a methanogenic bacterium, Methanobrevibacter arboriphilus. J. Lipid Res., 27, 724-730 (1986).

19) Morth, S. and Tindall, B. J., Variation of polar lipid composition within haloalkaliphilic archaebacteria. Syst. Appl. Microbiol., 6, 247-250 (1985).

20) Nishihara, M. and Koga, Y., Extraction and composition of polar lipids from the archaebacterium Methanobacterium thermoautotrophicum: Effective extraction of tetraether lipids by an acidified solvent. J. Biochem., 101, 997-1005 (1987).

21) Nishihara, M., Morii, H., and Koga, Y., Structure determination of a quartet of novel tetraether lipids from Methanobacterium thermoautotrophicum. J. Biochem., 101, 1007-1015 (1987).

22) Ollivier, B. M., Mah, R. A., Garcia, J. L., and Boone, D. R., Isolation and characterization of Methanogenium bourgense sp. nov. Int. J. Syst. Bacteriol., 36, 297--301 (1986).

23) Paynter, M. J. B. and Hungate, R. E., Characterization of Methanomicrobium mobilis, sp. n., isolated from the bovine rumen. J. Bacteriol., 95, 1943-1951 (1968).

24) Rivard, C. J., Henson, J. M., Thomas, M. V., and Smith, P. H., Isolation and characterization of Methanomicrobium paynteri sp. nov., a mesophilic methanogen isolated from marine sediments. Appl. Environ. Microbiol., 46, 484490 (1983).

25) Rivard, C. J., Henson, J. M., Thomas, M. V., and Smith, P. H., Isolation and characterization of Methanomicrobium paynteri sp. nov., a mesophilic methanogen isolated from marine sediments. Validation of the publication of new names and new combinations previously effectively published outside the IJSB. List No. 13. Int. J. Syst. Bacteriol., 34, 91 (1984).

26) Rivard, C. J. and Smith, P. H., Isolation and characterization of a thermophilic marine methanogenic bacterium, Methanogenium thermophilicum sp. nov. Int. J. Syst. Bacteriol., 32, 430-436 (1982).

27) Romesser, J. A., Wolfe, R. S., Mayer, F., Spiess, E., and Walther-Mauruschat, A., Methanogenium, a genus of marine methanogenic bacteria and characterization of Methanogenium cariaci spec. nov. and Methanogenium marisnigri spec. nov. Arch. Microbiol., 121, 147-153 (1979).

28) Ross, H. N. M. and Grant, W. D., Nucleic acid studies on halophilic archaebacteria. J. Gen. Microbiol., 131, 165-173 (1985). 
29) Scherer, P. and Kneifel H., Distribution of polyamines in methanogenic bacteria. J. Bacteriol., 154, 1315-1322 (1983).

30) Sleytr, U. B. and Messner, P., In Crystalline Bacterial Surface Layers, ed. by Sleytr, U. B., Messner, P., Pum, D., and Sára, M., Springer, Berlin, Heidelberg, and New York (1988), p. 160-186.

31) Sleytr, U. B., Messner, P., Sára, M., and Pum, D., Crystalline envelope layers in archaebacteria. Syst. Appl. Microbiol., 7, 310-313 (1986).

32) Stackebrandt, E., Ludwig, W., and Fox, G. E., 16S ribosomal RNA oligonucleotide cataloguing. In Methods in Microbiology, ed. by Gottschalk, G., Academic Press, London (1985), p. 75-107.

33) Thomm, M., Altenbuchner, J., and Stetter, K. O., Evidence for a plasmid in a methanogenic bacterium. J. Bacteriol., 153, 1060-1062 (1983).

34) Tindall, B. J., Qualitative and quantitative distribution of diether lipids in haloalkaliphilic archaebacteria. Syst. Appl. Microbiol., 6, 243-246 (1985).

35) Torreblanca, M., Rodriguez-Valera, F., Juez, G., Ventosa, A., Kamekura, M., and Kates, M., Classification of non-alkaliphilic halobacteria based on numerical taxonomy and polar lipid composition, and description of Haloarcula gen. nov., and Haloferax gen. nov. Syst. Appl. Microbiol., 8, 89-99 (1986).

36) Tu, J., Prangishvilli, D., Huber, H., Wildgruber, G., Zillig, W., and Stetter, K. O., Taxonomic relations between archaebacteria including 6 novel genera examined by cross hybridization of DNAs and 16S rRNAs. J. Mol. Evol., 18, 109-114 (1982).

37) Whitman, W. B., Methanogenic bacteria. In The Bacteria, Vol. VIII, A Treatise of Structure and Function, ed. by Woese, C. R. and Wolfe, R. S., Chap. 1, Academic Press, London (1985), p. 1-84.

38) Wildgruber, G., Thomm, M., König, H., Ober, K., Ricchiuto, T., and Stetter, K. O., Methanoplanus limicola, a plate-shaped methanogen representing a novel family, the Methanoplanaceae. Arch. Microbiol., 132, 31-36 (1982).

39) Winter, J., Maintenance of methanogenic stock cultures in the laboratory. Syst. Appl. Microbiol., 4, 558-563 (1983).

40) Zabel, H. P., König, H., and Winter, J., Isolation and characterization of a new coccoid methanogen, Methanogenium tatii spec. nov. from a solfataric field on Mount Tatio. Arch. Microbiol., 137, 308-315 (1984).

41) Zabel, H. P., König, H., and Winter, J., Emended description of Methanogenium thermophilicum, Rivard and Smith, and assignment of new isolates to this species. Syst. Appl. Microbiol., 6, 72-78 (1985).

42) Zellner, G., Alten, C., Stackebrandt, E., Conway de Macario, E., and Winter, J., Isolation and characterization of Methanocorpusculum parvum gen. nov., spec. nov., a new tungsten requiring, coccoid methanogen. Arch. Microbiol., 147, 13-20 (1987).

43) Zellner, G., Bleicher, K., Braun, E., Kneifel, H., Tindall, B. J., Conway de Macario, E., and Winter, J., Characterization of a new mesophilic, secondary alcohol-utilizing methanogen, Methanobacterium palustre spec. nov. from a peat bog. Arch. Microbiol., 151, 1-9 (1989).

44) Zellner, G., Stackebrandt, E., Messner, P., Tindall, B. J., Conway de Macario, E., Kneifel, H., Sleytr, U. B., and Winter, J., Methanocorpusculaceae fam. nov., represented by Methanocorpusculum parvum, Methanocorpusculum sinense spec. nov. and Methanocorpusculum bavaricum spec. nov. Arch. Microbiol., 151, 381-390 (1989).

45) Zellner, G. and Winter, J., Secondary alcohols as hydrogen donors for $\mathrm{CO}_{2}$-reduction by methanogens. FEMS Microbiol. Lett., 44, 323-328 (1987). 